\title{
POLIAMİD 6 POLIMERİ İLE POLİAMİD 6/VAKS KARIŞIMININ KENDİ ÜZERLERİNDE ÇALIŞMASI DURUMUNDAKİ TRİBOLOJİK DAVRANIŞLARININ İNCELENMESİ
}

\author{
Hüseyin ÜNAL ${ }^{1}$, Salih Hakan YETGİN ${ }^{2}$ \\ ${ }^{1}$ Sakarya Üniversitesi, Teknoloji Fakültesi, Metalurji ve Malzeme Mühendisliği Bölümü, Sakarya \\ ${ }^{2}$ Dumlupınar Üniversitesi, Simav Teknoloji Fakültesi, İmalat Mühendisliği Bölümü, Simav, Kütahya \\ unal@sakarya.edu.tr, hakan.yetgin@dpu.edu.tr
}

(Geliş/Received: 16.03.2015; Kabul/Accepted: 30.03.2016)

ÖZET

$\mathrm{Bu}$ çalışmada, katkısız poliamid 6 (PA 6) termoplastik polimeri ile katı yağlayıcı vaks katkılı poliamid 6 karışımının, kuru kayma şartları altında kendi üzerlerindeki tribolojik performansları incelenmiştir. Katı yağlayıcı vaks/poliamid 6 polimer karışımı ikiz vidalı endüstriyel amaçlı bir ekstruderde üretilmiş, test numuneleri ise enjeksiyon makinesi kullanılarak kalıplanmıştır. Tribolojik testler, ASTM G99 standardına uygun olarak yapılmıştır. Aşınma ve sürtünme testleri, disk üzerinde pim geometrisinde olan aşınma cihazında gerçekleştirilmiş olup $10 \mathrm{~N}, 20 \mathrm{~N}, 30 \mathrm{~N}, 50 \mathrm{~N}, 75 \mathrm{~N}, 100 \mathrm{~N}, 200 \mathrm{~N}$ ve $250 \mathrm{~N}$ yüklerde ve $0,5 \mathrm{~m} / \mathrm{s}$ kayma hızında gerçekleştirilmiştir. Tribolojik test sonuçlarına göre, katı yağlayıcı vaks karıştırılmış poliamid 6 polimerinin kendi üzerinde çalışması durumunda sürtünme katsayısı ve aşınma hızı özelliklerinin katkısız poliamid 6'ya göre daha iyi olduğu tespit edilmiştir. Katkısız poliamid 6 ve katı yağlayıcı vaks katkılı poliamid 6 karışımının aşınma yüzey mikro-yapıları incelemek için optik mikroskop kullanılmıştır.

Anahtar Kelimeler: Poliamid 6, triboloji, aşınma, sürtünme, vaks

\section{THE INVESTIGATION OF TRIBOLOGICAL PERFORMANCE OF POLYAMIDE 6 POLYMER AND POLYAMIDE 6/WAX BLEND AGAINST THEMSELVES}

\begin{abstract}
In the study, tribological performance of unfilled polyamide 6 and polyamide 6 blend with wax against themselves have been investigated. Wax filled polyamide 6 blend has been prepared by using an industrial type twin screw extruder. Tribological test samples have been produced by an injection moulding method according to ASTM G99 standard. Tribological tests were carried out on a pin-on-disc testing machine at loads of $10 \mathrm{~N}$, $20 \mathrm{~N}, 30 \mathrm{~N}, 50 \mathrm{~N}, 75 \mathrm{~N}, 100 \mathrm{~N}, 200 \mathrm{~N}$ and $250 \mathrm{~N}$ and sliding speed of $0.5 \mathrm{~m} / \mathrm{s}$. From the tribological results, it is concluded that coefficient of friction and specific wear rate values of polyamide 6/wax blend were lower than that of unfilled polyamide 6 . Optical microscope was used to investigate worn surfaces of polyamide 6 polymer and polyamide 6/wax blend.
\end{abstract}

Keywords: Polyamide 6, tribology, wear, friction, wax

\section{GIRISS (INTRODUCTION)}

Son yıllarda polimer esaslı kompozit malzemeler ve polimer karışımları endüstrinin değişik alanlarında oldukça yaygın olarak kullanılmaya başlamıştır. Polimer esaslı kompozit malzemeler, geleneksel malzemeler olan çelik, cam ve seramik malzemelerle karşılaştırıldığında yüksek dayanım/ağırlık oranı nedeniyle havacilık, otomotiv, elektrik-elektronik, makina ve kimya endüstrisi gibi endüstrinin değişik alanlarında artarak kullanılmaktadır. Ancak, katkısız polimer malzemeler, düşük mekanik, termal ve tribolojik özelliklere sahip olup genellikle endüstride kullanımı polimer kompozit malzemelere göre daha 
sınırlıdır [1, 2]. Makine endüstrisindeki aşınma ve sürtünme ile ilgili uygulamalar için katkısız polimerlerin mekanik özellikleri geliştirilmeli, aşınma direnci artırılmalı ve sürtünme katsayısı da azaltılmalıdır [3]. Polimerlerin özelliklerini geliştirmek için cam fiber, karbon fiber, aramid fiber, mineral fiber ve vollastonit gibi mukavemet artırıcılar ile kalsit, kaolin, talk ve mika gibi dolgular kullanılmaktadır. Buna ilaveten aşınma direncini artırmak ve sürtünme katsayısını düşürmek için ise $\mathrm{MoS}_{2}$, grafit, karbon siyahı, vaks ve poli-tetra-floretilen (PTFE) gibi katı yağlayıcılar kullanılmaktadır [4-9]. Katı yağlayıcılar genellikle polimer-çelik çifti sisteminde çelik karşı yüzeyinde sürekli transfer film tabakası oluşturarak sürtünme katsayısının azalmasına katkı sağlamaktadırlar [2, 10-12]. Poliamid 6 mühendislik polimerleri sinıfinda olup diğer geleneksel polimerler ile karşılaştırıldığında, üstün mekaniksel özellikleri nedeniyle elektrik/elektronik, otomotiv, ambalaj ve tekstil uygulamalarında yaygın olarak kullanım alanı bulan yüksek performanslı termoplastik bir polimerdir. [1]. Ancak, poliamid 6 polimerinin düşük 1sı sapma sıcaklığı, yüksek su emme özelliği ve ölçüsel kararsızlığı daha geniş uygulama alanlarında kullanımını sınırlandırmaktadır. Poliamid 6 polimerine katı yağlayıcılar ilave edilerek kullanım alanları daha da genişletilebilmektedir. Polimerlerin tribolojik davranışları çevre, proses şartları ve katkının tipi, boyutu ve miktarından etkilenmektedir [13]. Polimerlerin aşınma ve sürtünme davranışları üzerine literatürde birçok çalışmaya rastlanmaktadır. $\mathrm{Bu}$ çalışmalarda polimerlere ilave edilen katkı çeşidi ve miktarı, deney şartları, temas geometrisi ve çevre şartlarının etkisi araştırılmıştır. Ǘnal ve arkadaşları [14], cam fiber, bronz ve karbon fiber gibi katkiların PTFE polimerinin aşınma hızını azalttığını belirtmişlerdir. Ünal ve arkadaşlarının yaptığı bir başka çalışmada [1], katkısız PA6, ağırlık olarak \%5-15 oranında grafit katkılı PA6 kompozit ve \%4 vaks katk1lı PA6 polimer karışımı malzemelerinin paslanmaz çelik diske karşı kuru ortam şartları altındaki aşınma ve sürtünme davranışlarını incelemişlerdir. Çalışma sonucunda, katkısız PA6 ve grafit katkılı PA6 kompozitlerin artan kayma hızı ve uygulanan yük altında sürtünme katsayısı artmış, vaks katkılı polimer karışımının ise sürtünme katsayısı uygulanan yükten etkilenmemiştir. En düşük sürtünme katsayısı vaks katkılı PA6 polimer karışımında elde edilmiştir. Valeria ve arkadaşları [15], $\mathrm{MoS}_{2}$ katkılı yüksek yoğunluklu polietilen polimerinin aşınma davranışlarını incelemişlerdir. $\% 10$ oranında $\mathrm{MoS}_{2}$ katkılı yüksek yoğunluklu polietilen kompozitinde en iyi sürtünme ve aşınma davranışı elde edilmiştir. Yi-Lan ve arkadaşları [16] $\% 5$ nano- $\mathrm{TiO}_{2}$ katkılı PA6 polimer kompozitine $\mathrm{MoS}_{2}$, PTFE ve UHMWPE gibi yağlayıcılar ilave etmişler ve çalışmalarında ilave ettikleri katkıların kompozitin aşınma ve sürtünme davranışına etkilerini araştırmışlardır. PA6- $\% 5 \mathrm{TiO}_{2}$ polimer kompozitine ilave edilen katkı çeşidi ve katkı oranının artmasıyla sürtünme katsayısı ve aşınma hızının azaldığını belirtmişlerdir. Bolvari ve arkadaşları [17] PA66 polimeri, PA66/PTFE polimer karışımı ve aramid fiber katkılı PA 66 kompozitlerin takım çeliğine karşı aşınma ve sürtünme davranışlarını incelemişlerdir. Çalışma sonucunda aramid fiber katkılı PA66 kompozitinde, aramid fiber oranı arttıkça kompozitin çekme dayanımı artmıştır. \%10 PTFE/aramid fiber/PA66 polimer kompozitlerde ise çekme dayanımı pek etkilenmemiştir. PA 66'ya PTFE ilave edilmesiyle \%uzama, eğme ve darbe dayanımları azalmıştır. Aramid fiber/PA66 polimer kompozitlerde, aramid fiber miktarına bağlı olarak sürtünme katsayısı 0,6 civarında elde edilirken Aramid fiber/PA66/PTFE polimer kompozitlerde ise PTFE katkıdan dolayı sürtünme katsayısı $\% 50$ oranında azalmıştır. Palabıyık ve Bahadur [18] \%2080 YYPE katkılı PA6 polimer karışımlarının tribolojik özelliklerini incelemişlerdir. Çalışmalarını, uyumlaştırıcı kullanmadan ve uyumlaştırıcı kullanarak gerçekleştirmişlerdir. Çalışmaları sonucunda uyumlaştırıcı katkılı PA6'nın sürtünme katsayısı 0,81 olarak elde edilirken, PA6'ya ağırlıkça \%40 oranında YYPE ilave edilmesiyle sürtünme katsayısı 0,17 değerine kadar düşmüştür. Yani PA6/YYPE polimer karışımındaki YYPE polimeri, sürtünme katsayısının azalmasına sebep olmaktadır. Jayashree ve arkadaşları [19], kısa cam fiber (GF), PTFE ve $\mathrm{MoS}_{2}$ gibi katı yağlayıcı katkılı polietersülfon (PES) kompozitlerin aşınma davranışlarını incelemişlerdir. Çalışmalarında PTFE ve $\mathrm{MoS}_{2}$ gibi katı yağlayıcıların cam elyaf takviyeli PES kompozitlerin aşınma performanslarını iyileştirdiği gözlenmiştir. Çalışmalarında PTFE katı yağlayıcısının $\mathrm{MoS}_{2}{ }^{\prime}$ den daha etkili olduğunu belirtmişlerdir. Kısa cam elyaf ilavesi, PES polimerinin mekanik ve aşınma direncinin artmasında en etkili katkı elemanı olarak tespit edilmiştir. Poliamid 6 polimerinin aşınma ve sürtünme davranışını geliştirmek amacıyla genellikle mineral yağlar ve vaks katı yağlayıcısı kullanılmaktadır [6]. Kang ve Chung [20], döküm PA6 polimerine ilave ettikleri ağırlıkça \%2-8 oranlarındaki yağlayıcıların, polimerin mekanik ve tribolojik özelliklerine etkisini incelemişlerdir. Düşük basınç ve kayma hızlarında artan yağlayıcı miktarı ile sürtünme katsayısının azaldığını tespit etmişlerdir. Vaks katkılı PA 6, yağ ilaveli PA 6'ya göre daha düşük sürtünme katsayısı göstermiştir. Artan kayma hızı ve temas basıncı ile sürtünme katsayısının 0,08 değerine kadar azaldığını tespit etmişlerdir. Wang ve arkadaşları [21], karbon fiber ve $\mathrm{MoS}_{2}$ katkıların, poliamid 1010 polimerinin aşınma performansı üzerine etkilerini incelemişlerdir. $\mathrm{MoS}_{2}$, düşük yüklerde sürtünme katsayısını önemli oranda azaltırken, karbon fiber ise aşınma hızını azaltmıştır. $\mathrm{MoS}_{2}$ katkılı PA 6 kompoziti/çelik çiftinde çelik disk yüzeyinde oluşan transfer film tabakası daha kalın, karbon fiber/PA6 kompoziti/çelik disk çiftinde ise çelik disk yüzeyinde oluşan film tabakası ise daha ince, üniform ve sürekli olarak elde 
edilmiştir. Ünal ve arkadaşları [22] poliamid 6, polyoxy-methylene, çok yüksek molekül ağırlıklı polietilen, \%10 grafit katkılı poliamid 6, \%6vaks katkılı poliamid 6 ve $\% 10$ grafit / \%6 vaks katkılı poliamid 6 malzemelerinin aşınma ve sürtünme davranışlarını çelik disk üzerinde pim geometrisindeki cihazda yük ve hızın etkisine göre incelemişlerdir. Çalışmalarında vaks katkılı poliamid 6'nın sürtünme katsayısı hıza göre hafif artış gösterirken ortalama 0,1 civarında iken aşınma oranı ise yaklaşık olarak $8 \times 10$ $13 \mathrm{~m}^{2} / \mathrm{N}$ olarak tespit etmişlerdir. $\mathrm{Bu}$ deneysel çalışmada, katkısız poliamid 6 polimeri ile ağırlıkça $\% 6$ oranında katı yağlayıcı vaks katkılı poliamid 6 (PA6+\%6W) karışımının kendi üzerinde çalışmaları durumunda, kuru kayma şartları altında $10 \mathrm{~N}, 20 \mathrm{~N}$, $30 \mathrm{~N}, 50 \mathrm{~N}, 75 \mathrm{~N}, 100 \mathrm{~N}, 200 \mathrm{~N}$ ve $250 \mathrm{~N}$ olacak şekilde sekiz farklı yükte ve $0,5 \mathrm{~m} / \mathrm{s}$ kayma hızındaki tribolojik özellikleri incelenmiştir.

\section{DENEYSEL ÇALIŞMALAR (EXPERIMENTAL STUDY)}

\subsection{Malzeme ve Metot (Materials and Methods)}

Deneyde kullanılan yarı kristal yapılı poliamid 6 mühendislik polimeri Domopolimer firmasından temin edilmiştir. Vaks katı yağlayıcı katkı ise Konwax ticari adıyla Konya'dan temin edilmiştir. Tribolojik testlerde kullanılacak olan polimer pim numuneleri, $6 \mathrm{~mm}$ çapinda ve $50 \mathrm{~mm}$ uzunluğunda olacak şekilde enjeksiyonla kalıplama tekniği kullanılarak kalıpta basılmıştır. Enjeksiyon makinası ERAT marka olup enjeksiyon 1sitıcı sicaklıkları 220$240^{\circ} \mathrm{C}$ aralığında ayarlanmıştır. Enjeksiyonla kalıplama prosesi öncesi poliamid 6 polimeri $80^{\circ} \mathrm{C}^{\prime}$ de 4 saat firında kurutulmuştur. Aşınma ve sürtünme deneyleri, kuru ortam şartlarında, $23^{\circ} \mathrm{C}$ oda sıcaklığında ve Şekil 1'de şematik olarak verilen disk üzerinde pim geometrisine sahip aşınma cihazı kullanılarak Sakarya Üniversitesi, Teknoloji Fakültesi, Metalurji ve Malzeme Mühendisliği Triboloji laboratuarında gerçekleştirilmiştir. Aşınma ve sürtünme deneylerinde kullanılan malzeme çiftleri aşağıdaki gibi oluşturulmuştur. Poliamid $6 \mathrm{pim} /$ poliamid 6 disk ve poliamid $6+\% 6$ vaks pim/ poliamid $6+\% 6$ vaks disk. Poliamid 6 bünyesine ağırlıkça $\% 6$ oranında vaks ilavesi kompound makinesindeki üretim şartları (problemsiz maksimum üretilebilirlik) dikkate alınarak üretilmiştir. Her tribolojik test öncesi disk ve pim yüzeyleri asetonla temizlenip kurutulmuştur.

Tablo 1'de bu çalışmada kullanılan malzemeler için yoğunluk, çalışma ortam sıcaklığı, uygulanan yük ve kayma hızı gibi test şartları, Tablo 2'de ise polimer malzemelerin mekanik özellikleri verilmiștir. Şekil 1 'de şematik resmi görülen aşınma test cihazı, ana gövde üzerinde bir elektrik motoru, bir yük kolu, bir yük hücresi ve bilgisayar gibi kısımlardan oluşmaktadır. Makine üzerinde bir elektrik motorunun tahriği ile dönen sabit bir disk vardır. Bu sabit diskin üzerine ise deneylerde kullanılacak olan polimer disk malzemeler bir vida yardımıyla sabitlenir. Pim tutucu vasıtasıyla $6 \mathrm{~mm}$ çapındaki polimer pim malzemeler kola bağlanır. Kola bağlanan pim numunesi diskin üzerine yavaş̧a bırakılır, pim numunesinin diske teması ile birlikte pim numunesinin bağlı olduğu kol aparatı da diskin dönme yönüne doğru hareket etmeye zorlanmaktadır.

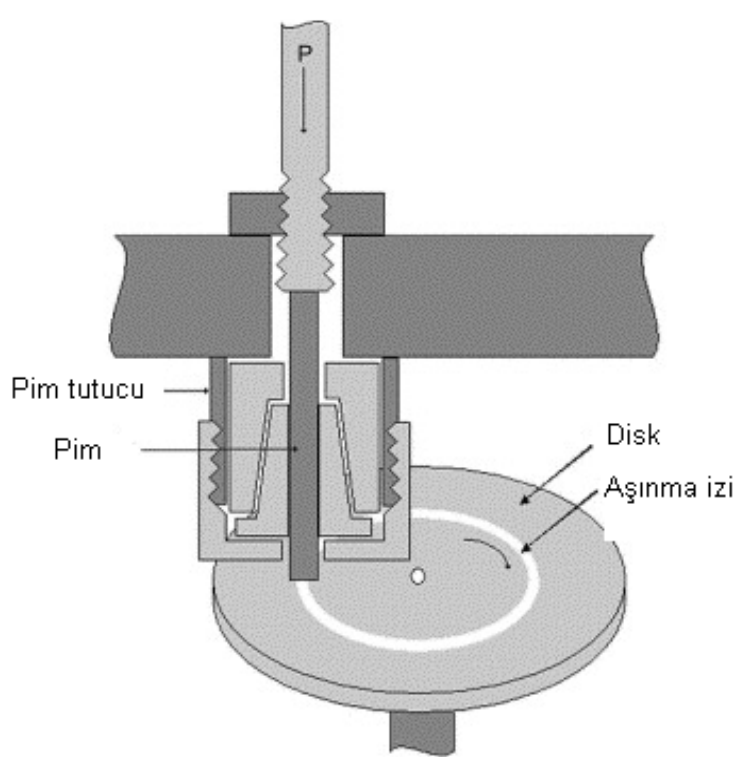

Şekil 1. Disk üzerinde pim geometrisine sahip aşınma test cihazı şematik görüntüsü (Schematic configuration of Pin-on-Disc machine employed for wear test)

$\mathrm{Bu}$ zorlanma sonucunda kolda diskin dönüş yönüne doğru bir hareket gerçekleşir. $\mathrm{Bu}$ hareket yanal kuvveti vermektedir. $\mathrm{Bu}$ yanal kuvvet ise bir yük hücresi (Load cell) ile ölçülmekte ve bu veriler dakikada 1000 veri alacak şekilde ayarlanıp, bilgisayarda Excel programına kaydedilmektedir. Ölçülen yanal yük değerleri, yine Excel programında deneylerde kullanılan normal yüke bölünerek sürtünme katsayısı elde edilir ve sürtünme katsayısı Eşitlik 1'de verilen formül ile hesaplanır.

$$
\mu=\frac{F_{S}}{F_{N}}
$$

Yukarıdaki formülde $\mu$ : Sürtünme katsayısını, $F_{S}$ : Yanal sürtünme kuvveti $(\mathrm{N})$ ve $\mathrm{F}_{\mathrm{N}}$ ise Normal kuvveti $(\mathrm{N})$ ifade eder.

Aşınma hızını belirlemek için her testten önce $\left(\mathrm{m}_{1}\right)$ ve sonra $\left(\mathrm{m}_{2}\right)$ pim ağırlıkları $0,1 \mathrm{mg}$ hassasiyetli ve $220 \mathrm{~g}$ kapasiteli PRECISA XB 220A marka dijital bir terazi ile ölçülerek ağırlık kaybı $(\Delta m)$ tespit edilmiştir. Eşitlik 2'de verilen formül ile de spesifik aşınma hızları $\left(K_{0}\right)$ hesaplanmıştır.

$$
K_{0}=\frac{\Delta_{m}}{L * \rho * F}\left(m^{2} / N\right)
$$


Tablo 1. Așınma ve sürtünme deneylerinde kullanılan polimer malzemeler ve deney şartları (The experimental conditions and polymer materials used in the friction and wear test)

\begin{tabular}{|c|c|c|c|c|c|}
\hline Malzeme & $\begin{array}{c}\text { Yoğunluk } \\
\left(\mathrm{g} / \mathrm{cm}^{3}\right)\end{array}$ & $\begin{array}{c}\text { Ortam Sicaklığ } 1 \\
\left({ }^{\circ} \mathrm{C}\right)\end{array}$ & Kayma & Kayma hızı & $\begin{array}{c}\text { Uygulanan Yük } \\
\text { (N) }\end{array}$ \\
\hline \multirow{3}{*}{ PA6 } & \multirow{3}{*}{1,13} & \multirow{8}{*}{$23 \pm 2$} & \multirow{8}{*}{1000} & \multirow{8}{*}{$0,5 \mathrm{~m} / \mathrm{s}$} & 10 \\
\hline & & & & & 20 \\
\hline & & & & & 30 \\
\hline \multirow{5}{*}{ PA6+\%6Vaks } & \multirow{5}{*}{1,11} & & & & 50 \\
\hline & & & & & 75 \\
\hline & & & & & 100 \\
\hline & & & & & 200 \\
\hline & & & & & 250 \\
\hline
\end{tabular}

Tablo 2. Deneylerde kullanılan malzemelerin mekanik ve fiziksel özellikleri (Physical and mechanical properties of materials used in the friction and wear test)

\begin{tabular}{ccccc}
\hline Malzemeler & $\begin{array}{c}\text { Çekme mukavemeti } \\
\text { (MPa) } \\
\text { (ASTM D638) }\end{array}$ & $\begin{array}{c}\text { Elastiklik Modülü } \\
\text { (MPa) } \\
\text { (ASTM D638) }\end{array}$ & $\begin{array}{c}\text { \% uzama } \\
\text { (ASTM D 638) }\end{array}$ & $\begin{array}{c}\text { Sertlik, (Shore D) } \\
\text { (ASTM D 2240) }\end{array}$ \\
\hline Poliamid 6 & 69 & 2820 & 7 & 75 \\
Poliamid 6+\%6vaks & 65 & 2443 & 30 & 75 \\
\hline
\end{tabular}

\section{DENEYSEL BULGULAR VE TARTIŞMA (EXPERIMENTAL RESULTS AND DISCUSSION)}

Şekil 2'de katkısız PA6 polimeri ile PA6+\%6vaks polimer karıșımının $0,5 \mathrm{~m} / \mathrm{s}$ kayma hızında ve $30 \mathrm{~N}$ yük altındaki kayma mesafesi-sürtünme katsayısı arasındaki ilişki verilmiştir.

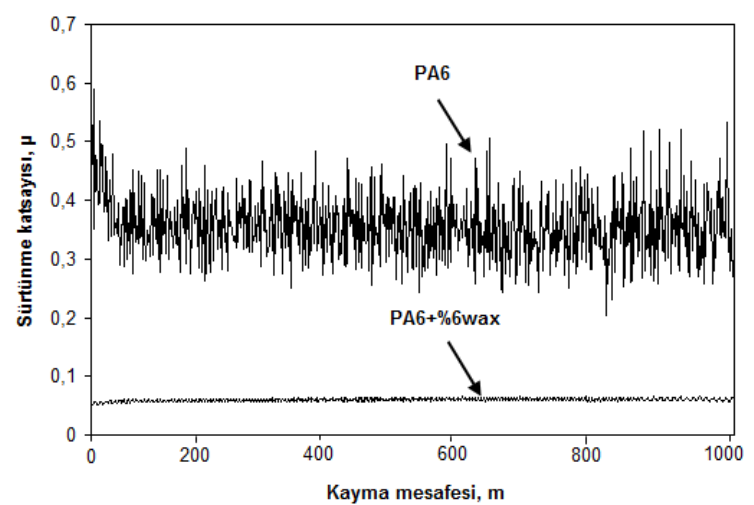

Şekil 2. Katkısız PA6 polimeri ile PA6+\%6vaks polimer karıșımının kendi üzerlerinde çalışması durumundaki sürtünme katsayıs1-kayma mesafesi ilişkisi (Kayma hızı: 0,5 m/s, Uygulanan Yük: 30N) (The relationship between coefficient of friction and sliding distance for pure polyamide 6 polymer and PA6-6\%wax blend against themselves (Sliding speed:0,5m/s, applied load:30N)

Şekilde görüldüğü gibi her iki polimer malzemenin de sürtünme katsayısı değişimi başlangıç ve sürekli kayma şartları olarak iki aşamada gerçekleşmiştir. Sürtünme katsayısı yaklaşık 100m kayma mesafesinden sonra kararlı hal aşamasına ulaşmıştır. Katkısız PA6 polimeri için başlangıç aşamasındaki sürtünme katsayısı kararlı hal aşamasındaki sürtünme katsayısından yüksek elde edilmiştir. Başlangıç aşaması süresince aşınma sonucu, sürtünen yüzeyler arasında ince partiküller şekillenmekte ve bu partiküller sürtünme yüzeyi üzerinde şekillenerek kararlı hal aşamasında sürtünme katsayısının azalmasina sebep olmaktadır [23]. PA6 polimerine ilave edilen katı yağlayıcı vaks katkısı sürtünme katsayısını önemli oranda azaltmasına sebep olmuştur. Sürtünme katsayısı PA6 polimeri için ortalama 0,42 elde edilirken \%6vaks katkılı PA6 polimeri için ise ortalama 0,05 elde edilmiștir. Benzer sonuçlar Du-Xin ve arkadaşları [24] tarafindan yapılan UHMWPE ve PTFE katkılı PA6 polimer numunelerinde de elde edilmiştir. PA6 polimerinin sürtünme pikleri geniş bir pik aralığında oluşurken PA6 polimerine ilave edilen vaks katkısı hem sürtünme katsayısını hem de pik genişliğini azaltmıştır. Bunun sebebi ise vaks katkısının karşı yüzeyde transfer film tabakası oluşturarak sürtünmeye karşı direnci düşürmesidir.

Şekil 3'de katkısız PA6 polimeri ile PA6+\%6vaks polimer karışımının kendi üzerlerinde çalışması durumunda elde edilen sürtünme katsayılarının uygulanan yük ile değişimi verilmektedir. Katkısız PA6 polimerinde, yüksek yükler altında (50N ve üzeri) çok kısa test süresi içinde aşırı derecede malzeme kaybı meydana gelmiştir. $\mathrm{Bu}$ sebeple, aşınma deneyleri katkısız PA6 polimeri için yüksek 
yüklerde gerçekleştirilememiştir. Katkısız PA6 polimerinde uygulanan yük ile sürtünme katsayısı önemli oranda azalırken \%6vaks katk1lı PA6 polimer numunesinde uygulanan yük sürtünme katsayısını etkilememiştir. En yüksek sürtünme katsayısı, 10N yük altında ve $0,5 \mathrm{~m} / \mathrm{s}$ kayma hızında 0,52 olarak katkısız PA6 polimerinde elde edilirken, en düşük sürtünme katsayıs1 ise PA6+\%6vaks polimer numunesinde 0,046 değeri ile $200 \mathrm{~N}$ yük altında elde edilmiştir. 30N sabit yük altında, PA6 polimerine ilave edilen ağırlıkça \%6 oranındaki vaks, polimerin sürtünme katsayısını \%81 oranında azaltmıştır. Bilindiği gibi polimerler visko-elastik davranış gösterirler ve yük altındaki deformasyonları viskoelastiktir. Bu yüzden, uygulanan yük veya basınç ile sürtünme katsayısının değişimi $\mu=\mathrm{KxL}^{(\mathrm{n}-1)}$ ile açıklanabilir. Burada, $\mu$ : sürtünme katsayısı, K: sabit, n: sabit $(0.66<\mathrm{n}<1$ arasındadır $)$, L: uygulanan yüktür. $\mathrm{Bu}$ eşitliğe göre, artan yük ile sürtünme katsayısı azalmaktadır. Yapılan çalışma sonuçlarından kullanılan yük değerlerinin, PA6/vaks polimer karışımı çifti için kritik yük değerinin aşılmadığı sonucuna varılmıştır. Fakat, uygulanan yük polimerin kritik yük taşıma kapasitesini aştığında, polimer malzemenin kritik yüzey enerjisinin artması sonucunda sürtünme ve aşınma artmaktadır. $\mathrm{Bu}$ davranış, sürtünme gücü $(\mu \mathrm{NV})$ veya spesifik enerji girişi $(\mu \mathrm{PV})$ olarak tanımlanan bu davranış sürtünme yüzeylerinde sıcaklığı artırarak polimer molekül zincirlerinin gevşemesine ve dolayısıyla yumuşamasına neden olur.

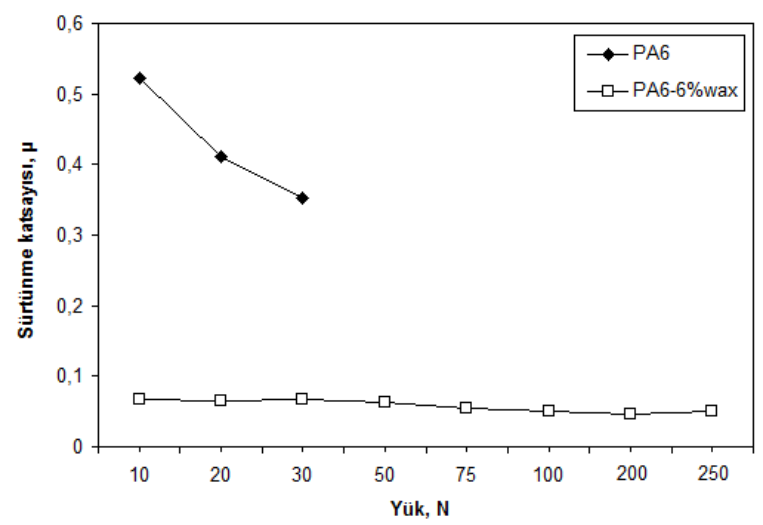

Şekil 3. PA6 polimeri ile PA6+\%6vaks polimer karışımının kendi üzerlerinde çalışması durumundaki sürtünme katsayısı-yük ilişkisi (The relationship between coefficient of friction and applied load for pure polyamide 6 polymer and PA6-6\% wax blend against themselves)

Şekil 4 PA6 polimeri ve PA6+\%6vaks polimer karışımının kendi üzerleri üzerinde çalışması durumundaki spesifik aşınma hızı ile uygulanan yük arasındaki ilişkiyi göstermektedir. PA6 polimerinin kendi üzerinde çalışması durumunda $10 \mathrm{~N}$ ile $30 \mathrm{~N}$ yük aralığında yükün artması ile aşınma hızı artmıştır. Spesifik aşınma hızındaki bu artış yaklaşık olarak $\% 80$ oranında olmuştur. PA6+\%6vaks polimer karışımının kendi üzerinde $10 \mathrm{~N}$ ile $50 \mathrm{~N}$ yük aralığında çalışması durumunda ise aşınma hızının azaldığı belirlenmiştir. Uygulanan yükün $\% 400$ artırılmasıyla spesifik aşınma hızındaki azalma yaklaşık olarak \%66'dır. $50 \mathrm{~N}$ yük ile $250 \mathrm{~N}$ yük aralığında ise aşınma hızında önemli bir değişim olmadığ üzerinde çalışması durumunda $30 \mathrm{~N}$ yük üzerinde çalışması mümkün olmamıştır. Sebebi ise, PA6/PA6 polimer çifti bu yüklerin üzerinde oldukça yüksek aşınma göstermesidir.

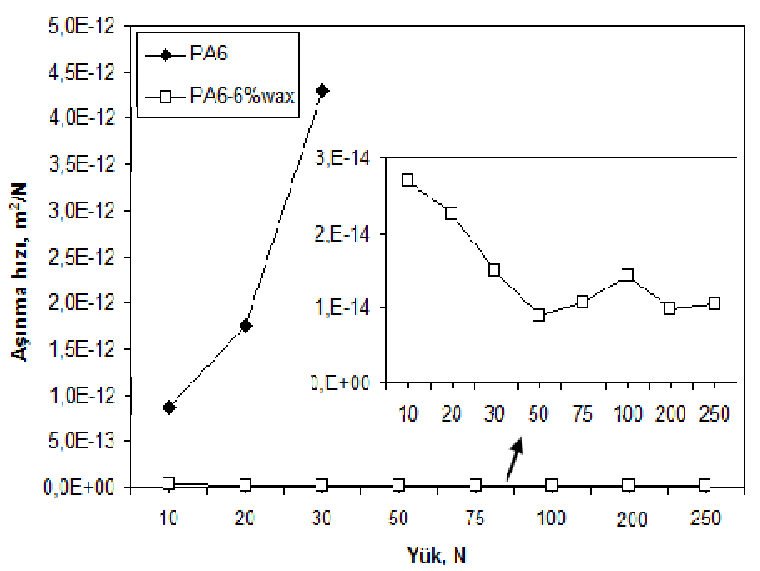

Şekil 4. PA6 polimeri ile PA6+\%6vaks polimer karışımının kendi üzerlerinde çalışması sonucundaki spesifik aşınma hızı - uygulanan yük ilişkisi (The relationship between coefficient of friction and specific wear rate for pure polyamide 6 polymer and PA6-6\%wax blend against themselves )

Şekil 5'a ve b'de sırasıyla PA6+\%6vaks polimerinin kuru ortam şartlarındaki pim ve disk aşınma yüzeyi optik mikroskop görüntüleri sırasıyla verilmiştir. Optik mikroskop görüntülerinden görüldüğü gibi katkısız PA6 pim polimerinin aşınma yüzeyinde vaks katkılı PA6 pim polimerine göre daha derin aşınma izleri görülmektedir (Bkz. Şekil 5a). Hatta karşı disk malzemesi olan PA6 disk polimerinin yüzeyinde ise aşınma izleri daha derin ve geniş olarak görülmektedir. (Bkz. Şekil 5b). Burada abrazif aşınma mekanizması şeklinde olduğu ifade edilebilir. Çünkü aşınma deneyleri sırasında PA6 pim/PA6 disk aşınma çifti çalışması süresince PA 6 disk yüzeyinde küçük aşınma partiküller gözlenmiştir. \%6 vaks katkılı PA6 polimer karışımının aşınma deneyleri sırasında ise disk yüzeylerinde herhangi bir partikül gözlenmemiştir.

\%6 vaks katkılı PA6 polimer karışımının pim ve disk optik mikroskop mikroyapısı incelendiğinde, hem pim hem de disk aşınma yüzeylerinin katkısız PA6'ya göre daha düzgün olduğu ve daha derin ve geniş olmayan aşınma izleri gözlenmektedir. Yüzey düzgünlüğü ve parlaklığının ise yağlayıcı özelliği olan vaks katkıdan dolayı olduğu düşünülmektedir ve polimere ilave edilen vaks katkı, poliamid polimer malzemenin aşınma direncinin artmasına ve sürtünme katsayısının azalmasına sebep olmaktadır. (Bakınız Şekil 3, Şekil 4). Bu elde edilen sonuçlar ise daha önce yapılan çalışmalarla [22] uyum içindedir. 


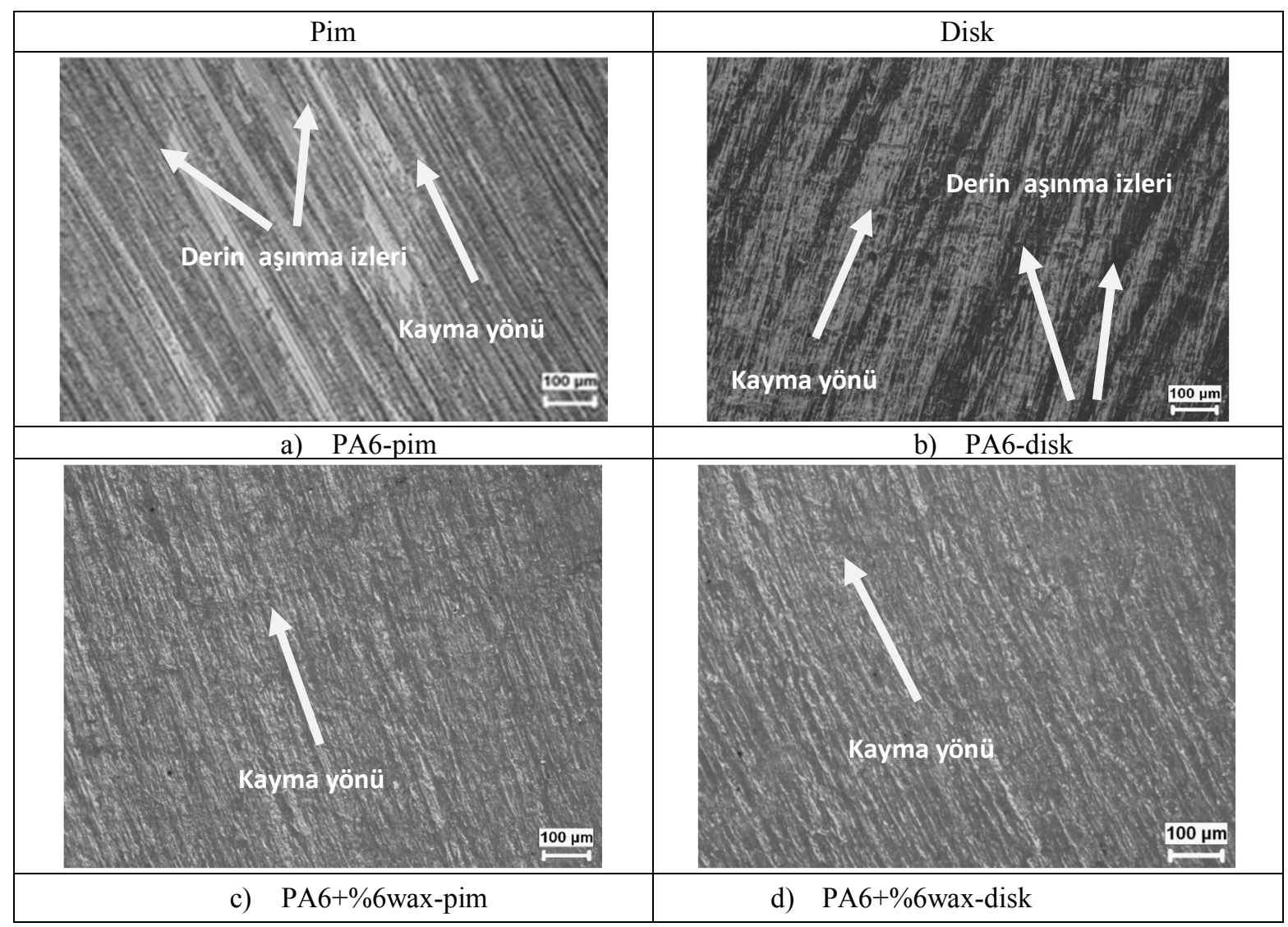

Şekil 5. Deneylerde kullanılan polimer malzemelerin aşınma yüzeyi optik mikroskop görüntüleri a) PA6 polimer pim, b) PA6 polimer disk, c) PA6+\%6wax polimer karışımı pim d) PA6+\%6wax polimer karışımı disk (uygulanan yük: $30 \mathrm{~N}$, kayma hızı:0,5m/s) (The optical micrographs of pin and disc surfaces for a) pure polyamide 6 polymer pin b) pure polyamide 6 polymer disc, c) PA6-6\%wax polymer blend pin d) PA6-6\%wax polymer blend disc (Sliding speed:0,5 $\mathrm{m} / \mathrm{s}$, applied load:30N)

\section{SONUÇLAR (CONCLUSIONS)}

Katkısız PA 6 polimeri ile PA $6+\% 6$ vaks polimer karışımının tribolojik testleri sonucunda aşağıdaki sonuçlar elde edilmiştir:

Katkısız PA6 polimeri için uygulanan yük (10N-30N) ile sürtünme katsayısı önemli oranda azalırken (0,52'den 0,36), \%6vaks katkılı PA6 polimer karışımının sürtünme katsayısı uygulanan yükten pek etkilenmemiş̧ir. PA 6 polimerine ilave edilen ağırlıkça \%6 oranındaki vaks, PA6/vaks polimer karışımının sürtünme katsayısının ortalama $\% 81$ oranında azaltmasına sebep olmuştur. Katkısız PA6 polimerinin aşınma hızı $10^{-12} \mathrm{~m}^{2} / \mathrm{N}$ değerlerinde elde edilirken, \%6vaks katkılı PA 6 polimer karışımının aşınma hızı ise $10^{-14} \mathrm{~m}^{2} / \mathrm{N}$ değerlerinde elde edilmiştir. PA 6 polimer ana matrisine ilave edilen ağırlıkça \%6 oranındaki vaks, PA6/vaks polimer karışımının aşınma hızının yaklaşık \%99 oranında azaltmasına sebep olmaktadır.

PA6+\%6vaks/PA6+\%6vaks polimer çifti, PA6/PA6 aşınma çiftine göre uygulanan deney şartları altında en iyi aşınma ve sürtünme davranışı sergilemektedir.

\section{SEMBOLLER VE KISALTMALAR (SYMBOLS AND ABBREVIATIONS)}
$\Delta \mathrm{m}: \quad$ Ağırlık kaybı $(\mathrm{g})$
L: $\quad$ Kayma mesafesi (m)
$\rho: \quad$ malzemelerin yoğunluğu $\left(\mathrm{g} / \mathrm{cm}^{3}\right)$
F: $\quad$ uygulanan yük $(\mathrm{N})$

\section{KAYNAKLAR (REFERENCES)}

1. Ünal, H., Mimaroglu, A., "Friction and wear performance of polyamide 6 and graphite and wax polyamide 6 composites under dry sliding conditions", Wear, 289, 132-137, 2012.

2. Chang, L., Zhang, Z., Zhang, H. ve Schlarb, A.K., "On the sliding wear of nanoparticle filled polyamide 66 composites", Composites Science and Technology, 66, 3188-3198, 2006.

3. Shivamurthy, B., Udaya Bhat, K. ve Anandhan, S., "Mechanical and sliding wear properties of multi-layered laminates from glass fabric/graphite/epoxy composites", Materials and Design, 44, 136-143, 2013.

4. Gai, Z., Irina, H., Maksim, A., Qihua, W., Tingmei, W. ve Der-Liang, Y., "Effect of temperature on sliding and erosive wear of fiber 
reinforced polyimide hybrids", Tribology International, 82, 525-533.

5. Cho, M.H., Bahadur, S. ve Pogosian, A.K., "Friction and wear studies using Taguchi method on polyphenylene sulfide filled with a complex mixture of MoS2, A12O3, and other compounds", Wear, 258, 1825-1835, 2005.

6. Franke, R., Haase, I., Lehmann, D., Hupfer, B. ve Janke, A., "Manufacturing and tribological properties of sandwich materials with chemically bonded PTFE-PA 66 and PA 66/GF", Wear, 262, 958-971, 2007.

7. Krawiec, S.T., "The influence of polymer fillers in a grease lubricant on the tribological performance of friction nodes operating under mixed friction conditions", Archives of Civil and Mechanical Engineering, 7-4, 121-128, 2007.

8. Anne, B., Sherry, G., Rob, J. ve Chris, E., "Wear and friction of aramid fiber and polytetrafluoroethylene filled composites", Wear, 203-204, 697-702, 1997.

9. Yetgin, S. H., Unal, H., Mimaroglu, A. ve Findik, F., "Influence of Process Parameters on the Mechanical and Foaming Properties of PP Polymer and PP/TALC/EPDM Composites" Polymer-Plastics Technology and Engineering, 52: 433-439, 2013.

10. Bahadur, S., "The development of transfer layers and their role in polymer tribology", Wear, 245, 92-99, 2000.

11. Bahadur, S. ve Polineni, V.K., "Tribological studies of glass fabricreinforced polyamide composites filled with $\mathrm{CuO}$ and PTFE", Wear, 200, 95-104, 2000.

12. Cenna, A.A., Dastoor, P., Beehag, A. ve Page, N.W., "Effects of graphite particle addition upon the abrasive wear of polymer surfaces", Journal of Materials Science, 36, 891-900, 2001.

13. Kukureka, S.N., Chen, Y.K., Hooke, C.J. ve Liao, P., "The wear mechanisms of acetal in unlubricated rolling-sliding contact", Wear, 185, 1-8, 1995.

14. Ünal, H., Mimaroglu, A., Kadioglu, U. ve Ekiz, H., "Sliding friction and wear behaviour of polytetrafluoroethylene and its composites under dry conditions", Materials and Design, Cilt 25, No 3, 239-245, 2004.

15. Valeria, P., Maria, J. C., David, F., Joseph, K.K. ve Patricia, M. F., "Changes in tribological performance of high molecular weight high density polyethylene induced by the addition of molybdenum disulphide particles, Wear, 269, 31-45, 2010.

16. Yi-Lan, Y., Du-Xin, L., Gao-Jie, Si. ve Xin, D., "Investigation of the influence of solid lubricants on thetribological properties of polyamide 6 nanocomposite", Wear, 311, 57-64, 2014.

17. Bolvari, A., Glenn, S., Janssen, R. ve Ellis, C., "Wear and friction of aramide fiber and polytetrafluoroethylene filled composites", Wear, 203-204, 697-702, 1997.

18. Palabıyık, M. ve Bahadur, S., "Mechanical and tribilogical properties of polyamide 6 and high density polyethylene polyblends with and without compatibilizer", Wear, 246, 149-158, 2000.

19. Jayashree, B., John, J. R., Jeyakumar , A., Ghosh, A. ve Tewari, U.S., "Influence of solid lubricants and fibre reinforcement on wear behaviour of polyethersulphone", Tribology International, 33, 697-706, 2000.

20. Kang, S.C. ve Chung, D.W., "The synthesis and frictional properties of lubricant-impregnated cast nylons, Wear, 239, 244-250, 2000.

21. Wang, J., Gu, M., Songhao, B. ve Ge, S., "Investigation of the influence of MoS2 filler on the tribological properties of carbon fiber reinforced nylon 1010 composites, Wear, 255, 774-779, 2003.

22. Ünal $H$ ve Mimaroglu A., "Comparison of tribological performance of some neat polymer and polymers composites", Surface Engineering, Cilt 29, No 6, 455-461, 2013.

23. Zhang, X.R., Pei, X.Q. ve Qi-Hua, W., "Friction and wear studies of polyimide composites filled with short carbon fibers and graphite and micro $\mathrm{SiO}_{2}$ ", Materials and Design, 30, 4414-4420, 2009.

24. Du-Xin, L, Yi-Lan, Y., Xin, D., Wen-Juan, L. ve Ying, X., "Tribological properties of solid lubricants filled glass fiber reinforced polyamide 6 composites, Materials and Design, 46, 809$815,2013$. 
